\title{
Adsorption of selected pharmaceuticals on activated carbons from water
}

\author{
Joanna Lach ${ }^{1, *}$, Anna Szymonik ${ }^{1}$, and Agnieszka Ociepa-Kubicka ${ }^{2}$ \\ ${ }^{1}$ Czestochowa University of Technology, Faculty of Infrastructure and Environment, Brzeźnicka 60a, \\ 42-200 Częstochowa, Poland \\ ${ }^{2}$ Czestochowa University of Technology, Faculty of Management, Armii Krajowej 19 B, \\ 42-200 Częstochowa, Poland
}

\begin{abstract}
The possibility of using activated carbon for the removal of salicylic acid andiibuprofen sodium has been explored. These compounds are observed in crude and treated sewage and in surface water. The effect of $\mathrm{pH}$ on the adsorption efficiency was assessed. Tests were carried out from solutions with $\mathrm{pH}$ ranging from 2 to 10 (salicylic acid) and from 6 to 10 (iibuprofen sodium). It was found that the higher $\mathrm{pH}$, the lower the adsorption of the compounds tested. Salicylic acid was most efficiently adsorbed from a solution with $\mathrm{pH}=2$, in which it occurred mainly in an undissociated form. The achieved efficiency of salicylic acid adsorption from solutions with $\mathrm{pH}=2$ was $91 \%$, while from those with $\mathrm{pH}=10$, it was $55 \%(\mathrm{Co}=4 \mathrm{mmol} / \mathrm{L})$. The efficiency of removing ibuprofen sodium from the $\mathrm{pH}=6$ solution was $64 \%$, while from the $\mathrm{pH}=10$ solution, $60 \%$. The adsorption of both salicylic acid and ibuprofen sodium follows the kinetics equation of the pseudo-2nd order. For the description of the adsorption isotherms, the Freundlich, Langmuir, Temkin and DubibinRadushkevich models were employed. The both compounds are described with the highest correlation coefficient in the case of the Freundlich equation.
\end{abstract}

\section{Introduction}

One of the problems involved with the development of civilization is environmental contamination with pharmaceuticals. Currently, they are observed in waste water, surface water, ground water, and even in drinking water [1-4].

The source of pharmaceuticals in surface water is chiefly sewage. Consumed pharmaceuticals are metabolised, though most often not completely. This means that the metabolic forms, as well as the free forms, of a medicine are excreted with urine [5]. They can be accumulated in contained home settling tanks and, as a result of infiltration, pass to ground water. The majority of sewage is discharged to the sewage system, whence it gets to a sewage treatment plant [6-8]. Pharmaceuticals are removed from sewage in conventional sewage treatment plants in a varying degree. In sewage treatment plants that use the activated sludge method, diclofenac is removed, in average, within the range

\footnotetext{
*Corresponding author: jlach@,is.pcz.czest.pl
} 
of $21-40 \%$ [9], naproxen within 50-80\% [10], while ketoprofen within $65-77 \%$ [10, 11 ]. Particularly large pharmaceutical loads are present in hospital sewage and in drug manufacturing plant waste water [3, 12]. Another source of pharmaceuticals in the environment is their improper disposal (unused drugs or those past their sell-by date). In that case, they find their way to a sewage system or a landfill, from where they can pass to ground or surface water $[6,8]$.

Particularly high concentrations of medicines are observed for products that are sold over the counter (OTC). This group of pharmaceuticals that are sold in very large quantities include non-steroidal anti-inflammatory drugs (NSAIDs). The following pharmaceutical concentrations were found in crude sewage: acetylsalicylic acid, $3.2 \mu \mathrm{g} / \mathrm{L}$; diclofenac, $3.02 \mu \mathrm{g} / \mathrm{L}$; ibuprofen, 1.2-2.68 $\mu \mathrm{g} / \mathrm{L}$; naproxen, $3.84 \mu \mathrm{g} / \mathrm{L}$; and ketoprofen, $2.9 \mu \mathrm{g} / \mathrm{L}[13$, 14]. An examination of crude sewage in a sewage treatment plant in Gdańsk found: ibuprofen in a concentration of $0.28 \mu \mathrm{g} / \mathrm{L}$; naproxen in a concentration of $0.24 \mu \mathrm{g} / \mathrm{L}$; diclofenac in a concentration of $0.46 \mu \mathrm{g} / \mathrm{L}$; and acetylsalicylic acid in a concentration of $1.4 \mu \mathrm{g} / \mathrm{L}$ [15]. Pharmaceuticals are also present in treated sewage. In the Bielsko-Biała sewage treatment plant, the presence of diclofenac in a concentration of $0.16 \mu \mathrm{g} / \mathrm{L}$ and naproxen in a concentration of $0.11 \mu \mathrm{g} / \mathrm{L}$ was found [16]. In 2014 Kotowska and coworkers examined crude and treated sewages originating from 9 sewage treatment plants in Poland. The highest concentrations in crude sewage were noted for: Ibuprofen $(34.5 \mu \mathrm{g} / \mathrm{L})$, naproxen $(27.8 \mu \mathrm{g} / \mathrm{L})$, ketoprofen $(21.6 \mu \mathrm{g} / \mathrm{L})$ and diclofenac $(1.21 \mu \mathrm{g} / \mathrm{L})$. The highest concentrations of these pharmaceuticals in treated sewage were as follows: ibuprofen $22.6 \mu \mathrm{g} / \mathrm{L}$, naproxen $-7.76 \mu \mathrm{g} / \mathrm{L}$ and diclofenac $-0.07 \mu \mathrm{g} / \mathrm{L}$ [17]. Of great concern is the fact that pharmaceuticals are also observed in drinking water [4].

Salicylates (sodium salicylate, magnesium salicylate, choline salicylate, cholinemagnesium salicylate) are products that are the components of many drugs available both by prescription and over the counter. A compound most often contained medicines, which becomes salicylic acid after consumption, is acetylsalicylic acid. This drug undergoes hydrolysis to yield salicylic acid [18].

Ibuprofen is a non-steroidal anti-inflammatory drug with a wide use worldwide. It is used as a drug for treating fever, pains of different origins and inflammatory conditions, e.g. in joints. It has been found that ibuprofen disturbs the hormonal management [19]. It is one of the drugs most often occurring in water [20].

The aim of this study is to examine the possibility of using commercial activated carbon for the removal of salicylic acid andibuprofen sodium from water solutions with different $\mathrm{pH}$ values.

\section{Materials and methods}

F-300 grade activated carbon was used for the tests. The description of the basic physical, chemical and adsorption properties of the activated carbon is given in Table 1.

Adsorption was conducted under static conditions from salicylic acid or Ibuprofen sodium solutions in the following concentrations: $1 ; 1.5 ; 2 ; 3$; and $4 \mathrm{mmol} / \mathrm{L}$, respectively. Change in $\mathrm{pH}$ was made using $\mathrm{HCl}$ or $\mathrm{NaOH}$ solutions. The presented test results are the average of three measurements. The adsorption was conducted from a solution with a volume of $0.25 \mathrm{~L}$, to which $1 \mathrm{~g}$ of activated carbon was added. To determine the time necessary for achieving the adsorption equilibrium, the solution in a concentration of $1 \mathrm{mmol} / \mathrm{L}$ was agitated at a rate of $160 \mathrm{rpm}$ for $10 \mathrm{hrs}$, and then allowed to stay for another $38 \mathrm{hrs}$. In the first phase, samples were taken every $1 \mathrm{hr}$, and then once a day.

Salicylic acid (Fig. 1) and ibuprofen sodium (Fig. 2) were purchased from SIGMA/ALDRICH. The molecular salicylic acid weight is $138.12 \mathrm{~g} / \mathrm{mol}$ and the linear 
formula $(\mathrm{HO}) \mathrm{C}_{6} \mathrm{H}_{4} \mathrm{CO}_{2} \mathrm{H}, \mathrm{pK}_{\mathrm{a}}$ 2.97. The concentration of ibuprofen sodium was determined spectrophotometrically at the wavelength of $\lambda=297 \mathrm{~nm}$.

The molecular ibuprofen sodium weight is $228.26 \mathrm{~g} / \mathrm{mol}$ and the linear formula $\mathrm{C}_{13} \mathrm{H}_{17} \mathrm{O}_{2} \mathrm{Na}$, $\mathrm{pK}_{\mathrm{a}}$ 4.91. The concentration of ibuprofen sodium was determined spectrophotometrically at the wavelength of $\lambda=230 \mathrm{~nm}$.

The adsorption isotherms were described with the Langmuir, Freundlich, Temkin and Dubibin-Radushkevich equations (Table 2).

Table 1. Physical and chemical properties of activated carbons (PN-83/C-97555) [21].

\begin{tabular}{|c|c|}
\hline Parameter & $\begin{array}{c}\text { Activated carbon } \\
\text { F-300 }\end{array}$ \\
\hline Bulk density, $\mathrm{g} / \mathrm{L}$ & 542 \\
\hline Surface area, $\mathrm{m}^{2} / \mathrm{g}$ & 859 \\
\hline Water absorption, $\mathrm{cm}^{3} / \mathrm{g}$ & 0.72 \\
\hline Mechanical strength, \% & 97 \\
\hline $\mathrm{pH}$ of water extract & 6.8 \\
\hline $\begin{array}{c}\text { Methylene blue number, } \mathrm{LM} \\
\text { Iodine adsorption, LI, } \mathrm{mg} / \mathrm{g}\end{array}$ & 31 \\
\hline
\end{tabular}<smiles>O=C(O)c1ccccc1O</smiles><smiles>CC(C)Cc1ccc(C(C)C(=O)O[Na])cc1</smiles>

Fig. 1. The structural formula of: $a-$ salicylic acid, $b$ - ibuprofen sodium.

Table 2. Isotherms and their linear forms [22].

\begin{tabular}{|c|c|c|c|}
\hline \multicolumn{2}{|c|}{ Isotherm } & Linear form & Plot \\
\hline Langmuir & $q=\frac{q_{m} K_{L} C_{e}}{1+K_{L} C_{e}}$ & $\frac{1}{q}=\left(\frac{1}{K_{L} \cdot q_{m}}\right) \frac{1}{C_{e}}+\frac{1}{q_{m}}$ & $1 / \mathrm{q}$ vs. $1 / \mathrm{C}_{\mathrm{e}}$ \\
\hline Freundlich & $q=K_{F} C_{e}^{\frac{1}{n}}$ & $\ln Q=\frac{1}{n} \ln C_{e}+\ln K_{F}$ & $\log \mathrm{q}$ vs. $\log \mathrm{C}_{\mathrm{e}}$ \\
\hline Temkin & $q=B \ln A_{T} C$ & $q=B \ln A_{T}+B \ln C$ & q vs. $\ln C_{\mathrm{e}}$ \\
\hline $\begin{array}{c}\text { Dubibin- } \\
\text { Radushkevich }\end{array}$ & $q=q_{s} \exp \left(-K_{D} \varepsilon^{2}\right)$ & $\ln q=\ln q_{s}-K_{D} \varepsilon^{2}$ & $\ln (\mathrm{q})$ vs. $\varepsilon^{2}$ \\
\hline
\end{tabular}

Pharmaceuticals where $q$ is the amount of metal ions adsorbed per unit mass of adsorbent $(\mathrm{mmol} / \mathrm{g}), C_{e}$ - equilibrium concentration of solute in bulk solution $(\mathrm{mmol} / \mathrm{L})$, $q_{m}$ - solid phase concentration corresponding to the complete monolayer coverage of adsorption sites, $K_{L}$ - the constant related to adsorption energy, $\mathrm{R}^{2}$ is the correlation coefficient, $K_{F}$ - Freundlich isotherm constant related to adsorption capacity, $n$ - constant related to adsorption intensity, $q_{s}$ is a constant in the Dubinin-Radushkevich isotherm model whit are related to adsorption capacity, $K_{D}$ is a constant in related to the mean free energy of adsorption, $\varepsilon$ Dubibin-Radushkevich ishoterm constant [22]. 
Various models have been suggested to describe the kinetics of adsorption of the solute molecules on the sorbent. The adsorption kinetics data were correlated with the adsorption kinetic models [23]:

- the pseudo-first-order kinetic model

$$
\log \left(q_{e}-q_{t}\right)=\log q_{e}-\frac{k_{1}}{2.303} t
$$

- the pseudo-second-order kinetic model

$$
\frac{t}{q_{t}}=\frac{1}{k_{2} q_{e}^{2}}+\frac{1}{q_{e}} t
$$

where:

$k_{1}$ - the rate constant for the pseudo-first-order kinetic model,

$k_{2}$ - the rate constant for the pseudo-second-order kinetic model,

$q_{e}-$ the amount of solute adsorbed et equilibrium and $q_{t}$ is the amount of solvent adsorbed at time $t$.

\section{Results and discussion}

At the first testing stage, the kinetics of the adsorption of salicylic acid and Ibuprofen sodium on F-300 activated carbon was examined (Fig. 2). Both compounds were adsorbed at the highest rate during the first 3 hours. A reduction in the concentration of either of the compounds by approx. $85 \%$ was obtained then. The establishment of the adsorption equilibrium was achieved for salicylic acid after $8.5 \mathrm{hrs}$, and for ibuprofen sodium after $9 \mathrm{hrs}$. The extension of the contact duration up to $48 \mathrm{hrs}$ did not increase the efficiency in the removal of the examined compounds. The equations of adsorption kinetics of the pseudo-1rst and 2nd order were established. For the contaminants under examination, the pseudo-2nd order kinetics equations describe the obtained testing results with a greater correlation coefficient $\mathrm{R}^{2}$, compared to the pseudo-1st order ones. On F-300 activated carbon, salicylic acid was adsorbed faster ibuprofen sodium (Table 3).

Salicylic acid occurs in either a dissociated or an undissociated form, depending on the $\mathrm{pH}$. The analysis of the influence of $\mathrm{pH}$ on the adsorption results is of particular importance. The $\mathrm{pH}$ has then an effect both on the state of the activated carbon surface and on the form of the adsorbed compound. The adsorption of salicylic acid is strongly linked with the $\mathrm{pH}$ of the solution (Fig. 3). It proceeds most efficiently from a solution with $\mathrm{pH}=2$. Clearly poorer adsorption effects were obtained when the $\mathrm{pH}$ was higher. It was observed that an increase in $\mathrm{pH}$ tended to lower the adsorption efficiency. However, the differences in adsorption between solutions with $\mathrm{pH} 4,6,8$ and 10 are not large. Similar trends were also observed by other authors $[24,25]$. In solutions with $\mathrm{pH}=2$, only approx. $9 \%$ of the compound are in a dissociated form; at $\mathrm{pH}=4$, more than $91 \%$ are already in a dissociated form; and at $\mathrm{pH}=6$, the compound is dissociated in $99 \%$ [26]. The degree of ionization of salicylic acid is most probably crucial to the adsorption efficiency. The efficiency of adsorption from a solution in a concentration of $4 \mathrm{mmol} / \mathrm{L}$ and at $\mathrm{pH}=2$ is about $91 \%$. In the case of adsorption from solutions with $\mathrm{pH}=2$, the compound under consideration is in more than $90 \%$ in the undissociated form which is better adsorbed than the ionic form. Also in the case of acid solutions, the surface of activated carbon is charged positively, which favours the adsorption of anions. The lowest adsorption efficiency was obtained from a solution with $\mathrm{pH}=10$. The complete dissociation of salicylic acid and the negative charge of the activated carbon surface have the effect of distinctly lowering the adsorption efficiency. In this case, for the highest salicylic acid concentration, an adsorption efficiency of $55 \%$ was obtained. 
a)

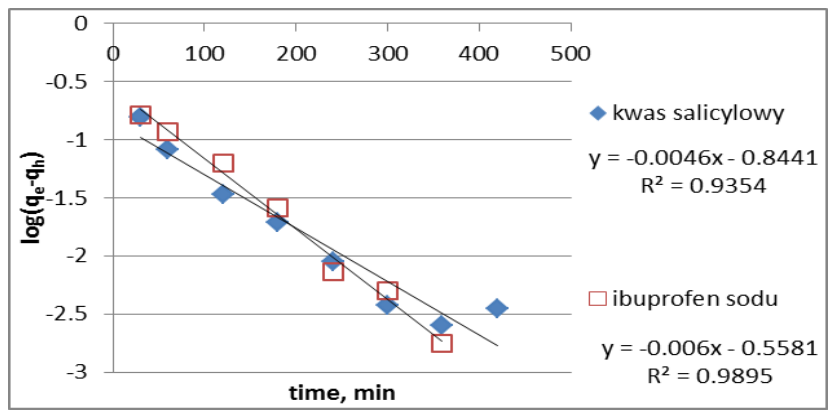

b)

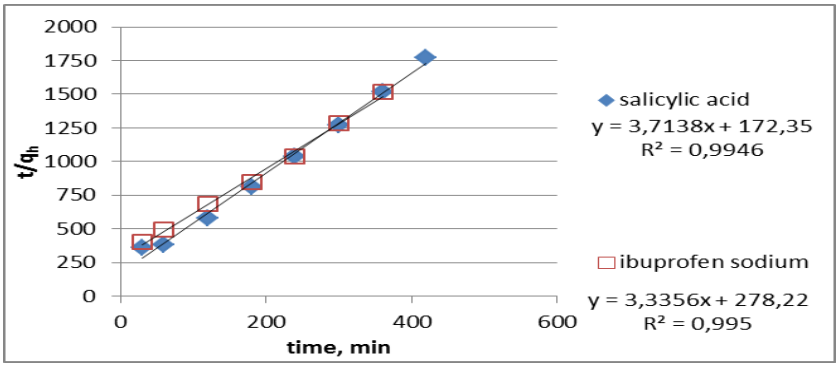

Fig. 2. Linearized kinetic model ibuprofen sodium $(\mathrm{pH}=6)$ and salicylic acid $(\mathrm{pH}=2)$ uptake by activated carbon F-300; a) pseudo-first-order kinetic model b) pseudo-second-order kinetic model.

Table 3. Kinetic parameters for ibuprofen sodium and salicylic acid.

\begin{tabular}{|c|c|c|c|}
\hline Equation of kinetics & Coefficient & Salicylic acid & Ibuprofen sodium \\
\hline \multirow{2}{*}{ Pseudo-first order } & $\mathrm{k}_{1}, 1 / \mathrm{min}$ & 0.0106 & 0.0138 \\
\cline { 2 - 4 } & $\mathrm{R}^{2}$ & 0.995 & 0.990 \\
\hline \multirow{2}{*}{ Pseudo-second order } & $\mathrm{k}_{2, \mathrm{mmol} /(\mathrm{g} \cdot \mathrm{min})}$ & 0.1005 & 0.0629 \\
\cline { 2 - 4 } & $\mathrm{R}^{2}$ & 0.994 & 0.995 \\
\hline
\end{tabular}

The obtained adsorption results were described by the Freundlich, Langmuir, Temkin and Dubibin-Radushkevich equations. The investigation results are best described by the Freundlich equation ( $\mathrm{R}^{2}$ from 0.949 to 0.991 ) followed by, in decreasing order, the Langmuir equation ( $\mathrm{R}^{2}$ from 0.900 to 0.966$)$, the Temkin equation $\left(\mathrm{R}^{2}\right.$ from 0.876 to 0.983 ), and lastly, the Dubibin-Radushkevich equation ( $R^{2}$ from 0.785 to 0.984 ) which is the poorest. All model types with a very high correlation coefficient describe adsorption from the solution with $\mathrm{pH}=2$ ( $\mathrm{R}^{2}$ from 0.958 to 0.983 ).

The adsorption ofibuprofen sodium was conducted in solutions with $\mathrm{pH}$ ranging from 6 to 10 , as this compound is very sparingly soluble in an acid medium. Similarly as for salicylic acid, the higher the $\mathrm{pH}$, the lower the adsorption efficiency (Fig. 4). The differences in adsorption efficiency between $\mathrm{pH} 6$ and $\mathrm{pH} 10$ are not large (a maximum of about $4 \%$ ). In the examined $\mathrm{pH}$ range, ibuprofen sodium occurs in more than $90 \%$ in an anion form (for $\mathrm{pH}=6.92 \%$; for $\mathrm{pH}=10.99 \%$ ). The higher the $\mathrm{pH}$, the greater the competition between the anions of Ibuprofen sodium and the hydroxide anions present in the water [27]. 
The adsorption isotherms of ibuprofen sodium acid were described with the highest correlation coefficient using the Freundlich equation ( $\mathrm{R}^{2}$ from 0.948 to 0.959). The remaining models (the Langmuir, Temkin and Dubibin-Radushkevich equations) describe the obtained results with a much lower correlation coefficient ( $\mathrm{R}^{2}$ from 0.751 to 0.872$)$. The lowest correlation coefficients were obtained when using the Dubibin-Radushkevich model.

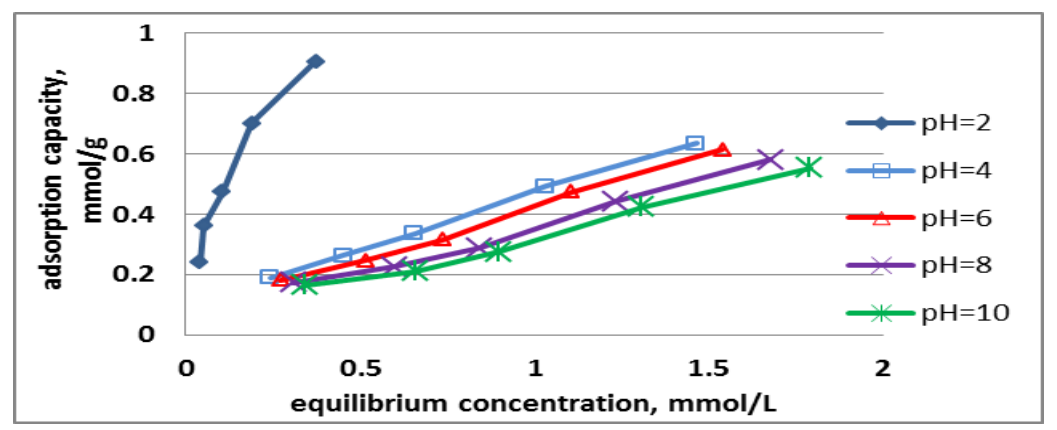

Fig. 3. Effect of the solution $\mathrm{pH}$ on the adsorption of salicylic acid.

Table 4. The values of Freundlich, Langmuir, Temkin and Dubibin-Radushkevich constants for the adsorption of salicylic acid.

\begin{tabular}{|c|c|c|c|c|c|c|}
\hline \multirow{3}{*}{ Isotherm } & \multirow{2}{*}{ Constants } & \multicolumn{5}{|c|}{ pH of the solution } \\
\cline { 3 - 7 } & & $\mathbf{2}$ & $\mathbf{4}$ & $\mathbf{6}$ & $\mathbf{8}$ & $\mathbf{1 0}$ \\
\hline \multirow{3}{*}{ Freundlich } & $\mathrm{K}_{\mathrm{F}, \mathrm{mmol} / \mathrm{g}}$ & 1.668 & 0.474 & 0.482 & 0.367 & 0.331 \\
\cline { 2 - 7 } & $1 / \mathrm{n},-$ & 0.56 & 0.68 & 0.72 & 0.73 & 0.75 \\
\cline { 2 - 7 } & $\mathrm{R}^{2}$ & 0.964 & 0.991 & 0.975 & 0.954 & 0.949 \\
\hline \multirow{3}{*}{ Langmuir } & $\mathrm{q}_{\mathrm{m}, \mathrm{mmol} / \mathrm{g}}$ & 1.283 & 0.896 & 0.885 & 0.877 & 0.754 \\
\cline { 2 - 7 } & $\mathrm{K}_{\mathrm{L}}, \mathrm{L} / \mathrm{mmol}$ & 6.346 & 1.052 & 0.942 & 0.877 & 0.754 \\
\cline { 2 - 7 } & $\mathrm{R}^{2}$ & 0.958 & 0.966 & 0.942 & 0.911 & 0.900 \\
\hline \multirow{3}{*}{ Temkin } & $\mathrm{A}, \mathrm{L} / \mathrm{mmol}$ & 60.010 & 7.327 & 6.186 & 5.271 & 4,662 \\
\cline { 2 - 7 } & $\mathrm{B},-$ & 0.287 & 0.248 & 0.249 & 0.238 & 0.234 \\
\cline { 2 - 7 } & $\mathrm{R}^{2}$ & 0.983 & 0.936 & 0.908 & 0.877 & 0,876 \\
\hline \multirow{3}{*}{$\begin{array}{c}\text { Dubibin- } \\
\text { Radushkevich }\end{array}$} & $\mathrm{q}_{\mathrm{s}, \mathrm{mmol} / \mathrm{g}}$ & 1.110 & 0.596 & 0.561 & 0.510 & 0.486 \\
\cline { 2 - 7 } & $\mathrm{K}_{\mathrm{D}, \mathrm{mol} / \mathrm{kJ}}$ & $2 \cdot 10^{-8}$ & $8 \cdot 10^{-8}$ & $9 \cdot 10^{-8}$ & $1 \cdot 10^{-7}$ & $1 \cdot 10^{-7}$ \\
\cline { 2 - 7 } & $\mathrm{R}^{2}$ & 0,974 & 0,885 & 0,843 & 0.796 & 0.785 \\
\hline
\end{tabular}

By comparing the adsorption of salicylic acid and ibuprofen sodium on F-300 activated carbon from solutions with identical $\mathrm{pH}$ values, slightly better results were obtained for the adsorption of ibuprofen sodium. However, the differences are small. 


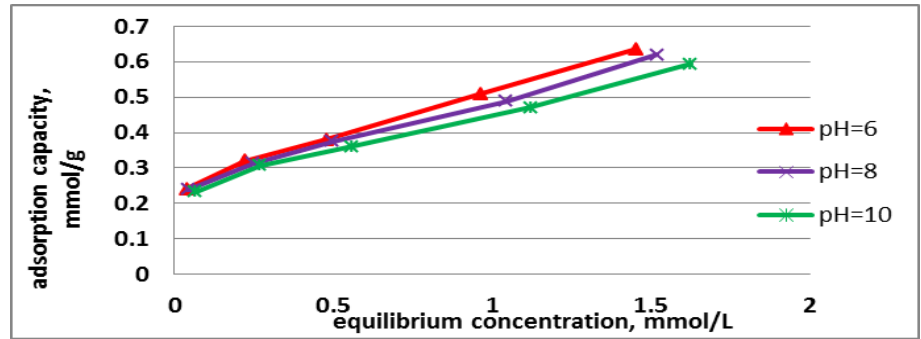

Fig. 4. Effect of the solution $\mathrm{pH}$ on the adsorption of ibuprofen sodium.

Table 5. The values of Freundlich, Langmuir, Temkin and Dubibin-Radushkevich constants for the adsorption of ibuprofen sodium.

\begin{tabular}{|c|c|c|c|c|}
\hline \multirow[t]{2}{*}{ Isotherm } & \multirow[t]{2}{*}{ Constants } & \multicolumn{3}{|c|}{ pH of the solution } \\
\hline & & 6 & 8 & 10 \\
\hline \multirow[t]{3}{*}{ Freundlich } & $\mathrm{K}_{\mathrm{F}}, \mathrm{mmol} / \mathrm{g}$ & 0.510 & 0.489 & 0.466 \\
\hline & $1 / \mathrm{n},-$ & 0.25 & 0.24 & 0.28 \\
\hline & $\mathrm{R}^{2}$ & 0.959 & 0.955 & 0.948 \\
\hline \multirow[t]{3}{*}{ Langmuir } & $\mathrm{q}_{\mathrm{m}}, \mathrm{mmol} / \mathrm{g}$ & 0.441 & 0.430 & 0.463 \\
\hline & $\begin{array}{c}\mathrm{K}_{\mathrm{L}}, \\
\mathrm{L} / \mathrm{mmol}\end{array}$ & 40.80 & 39.25 & 14.30 \\
\hline & $\mathrm{R}^{2}$ & 0.842 & 0.834 & 0.812 \\
\hline \multirow[t]{3}{*}{ Temkin } & $\begin{array}{c}\mathrm{A}, \\
\mathrm{L} / \mathrm{mmol}\end{array}$ & 338,56 & 340.50 & 97.31 \\
\hline & $\mathrm{B},-$ & 0.088 & 0.085 & 0.104 \\
\hline & $\mathrm{R}^{2}$ & 0.872 & 0.866 & 0,869 \\
\hline \multirow{3}{*}{$\begin{array}{c}\text { Dubibin- } \\
\text { Radushkevich }\end{array}$} & $\mathrm{q}_{\mathrm{s}}, \mathrm{mmol} / \mathrm{g}$ & 0.484 & 0.468 & 0.474 \\
\hline & $\mathrm{K}_{\mathrm{D}}, \mathrm{mol}^{2} / \mathrm{kJ}$ & $1 \cdot 10^{-8}$ & $1 \cdot 10^{-8}$ & $2 \cdot 10^{-8}$ \\
\hline & $\mathrm{R}^{2}$ & 0,815 & 0.804 & 0.751 \\
\hline
\end{tabular}

\section{Conclusions}

The adsorption of both salicylic acid and ibuprofen sodium on F-300 activated carbon follows the kinetics equation of the pseudo-2nd order. It has been found that salicylic acid is best adsorbed on F-300 activated carbon from a $\mathrm{pH}=2$ solution in which it occurs mainly in an undissociated form and can be bonded by means of physical sorption. It has been observed that the higher $\mathrm{pH}$, the lower the adsorption efficiency. For the highest concentration used in the tests, a 91\% salicylic acid removal degree was obtained from a $\mathrm{pH}=2$ solution, while from a $\mathrm{pH}=10$ solution, only a $55 \%$ removal degree. Increasing the degree of dissociation of salicylic acid in higher $\mathrm{pH}$ solutions causes a reduction in adsorption efficiency. The ion exchange of anions associated with the presence of alkaline-reaction surface groups on the activated carbon surface usually yields poorer results compared to the adsorption proper associated with van der Waals forces.

In the case of ibuprofen sodium, the process was conducted from solutions with $\mathrm{pH}$ ranging from 6 to 10 . In the examined $\mathrm{pH}$ range it has been noted that the higher the $\mathrm{pH}$, the lower the adsorption efficiency; nevertheless, the differences are not big.

By comparing the efficiency of adsorption of ibuprofen sodium and salicylic acid, a slightly better adsorption efficiency has been found for salicylic acid. The both compounds are described with the highest correlation coefficient when using the Freundlich 
equation, while with the lowest correlation coefficient, when using the DubibinRadushkevich model.

Acknowledgements: This research was financed from the statutory grant No. BS/PB - 401/301/12 i BS/MN 625/301/2015.

\section{References}

1. A.I.T. Carvalho, C.L. Santos, Environ. Int. 94, 736 (2016)

2. P. Calza, C. Medana, E. Padovano, V. Giancotti, C. Minero, Environ. Sci. Pollut. Res. Int. 20, 4, 2262 (2013)

3. R.J. Bull, J. Crook, M. Whittaker, J.A. Cotruvo, Regul. Toxicol. Pharmacol. 60, 1, $1(2011)$

4. A. Szymonik, J. Lach, K. Malińska, Ecol. Chem. Eng. S. 24, 1, 65 (2017)

5. W. Janiec, Kompendium farmakologii (Wydawnictwo Lekarskie PZWL, 2005)

6. J. Biernasiak, K. Śliżewska, Z. Libudzisz, Postępy Nauk Rolniczych 3, 105 (2010)

7. K.D. Brown, J. Kulis, B. Thomson, T.H. Chapman, D.B. Mawhinney, Sci. Total. Environ. 366, 772 (2006)

8. L.L. Bruton, J.S. Lazo, K.L. Parker, Farmakologia Goodmana \& Gilmana, (Wydawnictwo Czelej, Lublin, 2007)

9. Y. Zhang, S.U. Geißen, C. Gal, Chemosphere 73, 1151 (2008)

10. J. Radjenovi'c, M. Mato`si'c, I. Mijatovi'c, M. Petrovi'c, D. Barceló, Hdb. Env. Chem. 5, 37 (2008)

11. A. Nikolaou, S. Meric, D, Fatta, Anal. Bioanal. Chem. 387, 1225 (2007)

12. Q. Ashfaq et al., Environ. Toxicol. Pharmacol. 42, 6 (2016)

13. C. Zwiener, F.H. Frimmel. Sci. Total Environ. 309, 201 (2003)

14. J.H. Al-Rifai, C.L. Gabelish, Chemosphere 69, 803 (2007)

15. N. Migowska, M. Caban, P. Stepnowski, J. Kumirska, Sci. Total Environ. 441, 77 (2012)

16. I. Baranowska, B. Kowalski, Bull. Environ. Contam. Toxicol. 89, 8 (2012)

17. U. Kotowska, J. Kapelewska, J. Sturgulewska, Environ. Sci. Pollut. Res. 21, 660 (2014)

18. M. Otero, C.A. Grande, A.E. Rodrigues, React. Funct. Polym. 60, 203 (2004)

19. H.R. Buser, T. Poiger, M.D. Muller, Environ. Sci. Technol. 33, 2529 (1999)

20. P. Verlicchip, A. Galletti, M. Petrovic, D. Barcelo, J. Hydrol. 389, 416 (2010)

21. J. Lach, A. Ociepa-Kubicka, E3S Web of Conferences 19, 02008

22. K.Y. Foo, B.H. Hameed, Chem. Eng. J. 156, 2 (2010)

23. L. Largitte, R. Pasquier, Chem. Eng. Res. Des. 109, 495 (2016)

24. A.G. Karunanayake et al., Chem. Eng. J. 319, 75 (2017)

25. J. Liado, M. Sole-Sardans, C. Lao-Luque, F. Fuente, B. Ruiz, Process Saf. Environ. 104, 294 (2016)

26. A. Szymonik, J. Lach, Eng. Prot. Environ. 19, 3, 401 (2016)

27. M. Essnhdoh, B. Kunwar, C.U. Pittman Jr., D. Mohan, T. Mlsna, Chem. Eng. J. 265, 219 (2015) 